\title{
Novel case of food poisoning caused by the consumption of Pacific bluefin tuna infected with Kudoa hexapunctata
}

\author{
Takayuki Tachibana ${ }^{1}$ and TAKASHI WATARI ${ }^{2}$ \\ ${ }^{1}$ Shimane University \\ ${ }^{2}$ Shimane University Faculty of Medicine Graduate School of Medicine
}

November 23, 2020

\begin{abstract}
Consumption of Japanese cuisine, such as sushi and sashimi, is accompanied by the risk of food poisoning through various pathogens. Kudoa hexapunctata, detected in both adult and juvenile Pacific bluefin tuna, causes foodborne diseases. Here, we report cases of food poisoning after Kudoa hexapunctata-infected PBT consumption.
\end{abstract}

Novel case of food poisoning caused by the consumption of Pacific bluefin tuna infected with Kudoa hexapunctata

Takayuki Tachibana ${ }^{\mathrm{a}}$, Takashi Watari $\mathrm{b}^{*}$

${ }^{a}$ Faculty of Medicine, Shimane University, Shimane, Japan.

b Postgraduate Clinical Training Center, Shimane University Hospital, Shimane, Japan.

${ }^{*}$ Corresponding author:

Takashi Watari

89-1, Enya-cho, Izumo shi, Postgraduate Clinical Training Centre, Shimane University Hospital, Shimane 693-8501, Japan.

E-mail: wataritari@gmail.com

Phone: +81-853-20-2005 Fax:+81-853-20-2375

Abstract: Consumption of Japanese cuisine, such as sushi and sashimi, is accompanied by the risk of food poisoning through various pathogens. Kudoa hexapunctata, detected in both adult and juvenile Pacific bluefin tuna, causes foodborne diseases. Here, we report cases of food poisoning afterKudoa hexapunctata -infected PBT consumption.

Keywords: Kudoa hexapunctata, tuna, gastroenterology, infectious disease, food poisoning

Abbreviations: PBT, Pacific blue Tuna

Introduction

The Kudoa genus comprises more than 90 myxosporean parasitic species capable of infecting various marine fish ${ }^{[1]}$. In Japan, K. septempunctata was recently associated with food poisoning caused due to the consumption of infected raw olive flounder ${ }^{[2,3]}$. Until recently, infection potential of other members of the genus Kudoa in humans was unknown. However, in the past decade, Japanese researchers have reported foodborne diseases after the consumption of $K$. hexapunctata -infected adult or juvenile Pacific bluefin tuna 
(PBT) (Thunnus orientalis $)^{[4]}$. Until recently, K. hexapunctata was classified as an intraspecific variant of $K$. neothunni, but it has now been established as a separate species ${ }^{[5,6]}$; differing in spore shape, $28 \mathrm{~S}$ rDNA sequences, and potential to cause myoliquefaction, which is absent in K. hexapunctata. Although previous in vitro study suggested that $K$. hexapunctata causes food poisoning ${ }^{[4]}$, currently it is not listed as a food poisoning-related pathogen in Japan. Here, we report food poisoning in 10 patients after consumption of juvenile PBT infected with $K$. hexapunctata .

\section{Case report/Case history}

A 28-year-old man with severe diarrhea and nausea visited our emergency room after consuming food at a restaurant, along with 31 colleagues; as per the survey of the staff at the Izumo Health Center, 10 out of 32 individuals developed acute gastrointestinal symptoms several hours after the meal (attack rate, 31.3\%; incubation period [?] $7 \mathrm{~h}$; incubation distribution, 2-12 h) with diarrhea and nausea being the most common symptoms $(60.0 \%)$, followed by abdominal pain $(50.0 \%)$, and fever $(40.0 \%)$; the average number of bowel movements per day was approximately six (range: $4-8$ ), and mean temperature was $37.4{ }^{\circ} \mathrm{C}$ (range: $37.0-37.8$ $\left.{ }^{\circ} \mathrm{C}\right)$.

As all the patients had consumed sashimi prepared using juvenile PBT, food poisoning was suspected, and meal leftovers and stool specimens from the patients were submitted to the Shimane Prefectural Institute of Public Health and Environmental Science, Japan. PCR analysis revealed that four of the seven stool (three samples were missing) samples and leftover sashimi samples harbored Kudoa hexapunctata. In addition, Kudoa hexapunctata was observed microscopically in two samples collected from the leftover. (Fig. 1). No suspected food poisoning-related pathogens other than $K$. hexapunctata were detected in the stool samples. This diagnosis was made as all patients presented with transient diarrhea and vomiting, within a few hours of consuming sashimi containing juvenile PBT.

\section{Discussion}

In the present study, PCR analysis of the stool samples of seven patients and leftover sashimi (prepared from juvenile PBT) samples indicated $K$. hexapunctata infection. Previous studies have confirmed the presence of $K$. hexapunctata in both Japanese bluefin and yellowfin tuna, especially in PBT, with a higher rate of infection in juvenile than in adult fish. The K. hexapunctatapositivity rate in juvenile PBT from Japanese waters is generally high from May to July ${ }^{[4]}$. In the current study, juvenile PBT consumed by the patients were caught in early August, which is proximal to the aforementioned time-frame. Therefore, concurrent with the previous reports, we considered the $K$. hexapunctatapositivity rate in juvenile PBT consumed by the patients to be high ${ }^{[4]}$. Surveys of the clinical diarrhea due to tuna ingestion in Tokyo indicated a 5 -7-h incubation period until symptom onset ${ }^{[4]}$. In vitro studies have reported that the time lag until transepithelial electrical resistance (TER) across the Caco- 2 cell monolayer decreases by $80 \%$ in cell monolayer permeability assays, which are performed to assess $K$. hexapunctata toxicity in vitro. These results correlated with the incubation period reported in an epidemiological survey ${ }^{[4]}$. Rapid reduction in TER in an assay using the Caco-2 cell line, which has been widely used as an in vitro model for intestinal transport and enterotoxin studies, indicates the loss of human intestinal epithelial monolayer integrity, which is believed to cause diarrhea. ${ }^{[7]}$. The incubation period and primary symptom (diarrhea) observed herein are consistent with those reported previously ${ }^{[4]} . K$. hexapunctatadoes not cause gastrointestinal inflammatory symptoms, unless it is abundantly present in the raw fish consumed ${ }^{[4]}$. Hence, in the current study, some patients may not have developed gastrointestinal symptoms despite consuming the sashimi. However, few studies have evaluated the cases of food poisoning that are thought to be caused by $K$. hexapunctata. Therefore, it is necessary to investigate the suspected food poisoning cases caused by ingestion of adult or juvenile PBT.

Symptoms of the patients were resolved within a few days without specific treatments. However, in case of patients with severe symptoms, supportive care (infusion fluids, antiemetics, and antifebrile treatment) may be required. Currently, Japanese cuisine is the second-most popular cuisine worldwide ${ }^{[8]}$; therefore, further experimental, and epidemiological studies are required to elucidate the pathogenicity of $K$. hexapunctata . A patient's history and physical examination usually form the basis of diagnosis for acute gastroenteritis, 
as culture or blood tests are rarely performed. This increases the chances of underdiagnosis or misdiagnosis of acute gastroenteritis due to parasites, including K. septempunctata, and the condition is more commonly diagnosed as acute viral gastroenteritis. Thus, it is important to acquire information about the fish used in sashimi and sushi preparation (raw flounder and adult or juvenile PBT) from the patients for clarifying whether their gastrointestinal symptoms (e.g., vomiting and diarrhea) are associated with a Kudoa infection.

\section{Acknowledgments}

The authors would like to thank the staff of the Izumo Health Center for their kind help and Professor Kazumichi Onigata, Dean of Shimane University, Faculty of Medicine, for his valuable advice.

Authorship list: T.T and T.W almost equally contributed, data collection, data analysis and interpretation, drafting the article, and critical revision of the article.

\section{Funding}

This study did not receive grants from any funding agencies in the public, commercial, or not-for-profit sectors.

\section{Declarations of interest}

None

\section{Ethics approval}

Not applicable

\section{Consent to participate}

Patient consent was obtained prior to this study.

\section{Consent for publication}

Patient consent was obtained prior to this study.

\section{Availability of data and material}

Not applicable.

\section{References}

[1] Yokoyama, H., Grabner. D., Shirakashi, S. 2012. Transmission Biology of the Myxozoa. In: Carvalho ED, David GS, Silva RJ, editors. Health and Environment in Aquaculture, Croatia: InTech; https://doi.org/10.5772/29571.

[2] Kawai, T., Sekizuka, T., Yahata, Y., Kuroda, M., Kumeda, Y., Iijima, Y., Kamata, Y., Sugita-Konishi, Y., Ohnishi, T. 2012. Identification of Kudoa septempunctata as the causative agent of novel food poisoning outbreaks in Japan by consumption of Paralichthys olivaceus in raw fish. Clinical Infectious Diseases 54:10461052. https://doi.org/10.1093/cid/cir1040.

[3] Tachibana, T, and Watari, T. 2020. Kudoa septempunctatainfection: an underdiagnosed pathogen of acute gastrointestinal symptoms. QJM. 113:43-44. https://doi.org/10.1093/qjmed/hcz227.

[4] Suzuki, J., Murata, R., Yokoyama, H., Sadamasu, K., Kai, A. 2015. Detection rate of diarrhoea-causing Kudoa hexapunctata in Pacific bluefin tuna Thunnus orientalis from Japanese waters. International Journal of Food Microbiology 194:1-6. https://doi.org/10.1016/j.ijfoodmicro.2014.11.001.

[5] Abe, N., and Maehara, T. 2013. Molecular characterization of kudoid parasites (Myxozoa: Multivalvulida) from somatic muscles of Pacific bluefin (Thunnus orientalis ) and yellowfin (T. albacores ) tuna. Acta Parasitologica 58:226-230. https://doi.org/10.2478/s11686-013-0130-1. 
[6] Yokoyama, H., Suzuki, J., Shirakashi, S. 2014. Kudoa hexapunctata n. sp. (Myxozoa: Multivalvulida) from the somatic muscle of Pacific bluefin tuna Thunnus orientalis and re-description of $K$. neothunni in yellowfin tuna T. albacares . Parasitology International 63:571-579. https://doi.org/10.1016/j.parint.2014.03.006.

[7] Guarino, A., Canani, R.B., Casola, A., Pozio, E., Russo, R., Bruzzese, E., Fontana, M., Rubino, A. 1995. Human intestinal cryptosporidiosis: secretory diarrhoea and enterotoxic activity in Caco-2 cells. Journal of Infectious Diseases 171: 976-983. https://doi.org/10.1093/infdis/171.4.976

[8] Waldfogel, J. 2020. Dining out as cultural trade. Journal of Cultural Economics 44:309-338. https://doi.org/10.1007/s10824-019-09360-5.

\section{Figure caption}

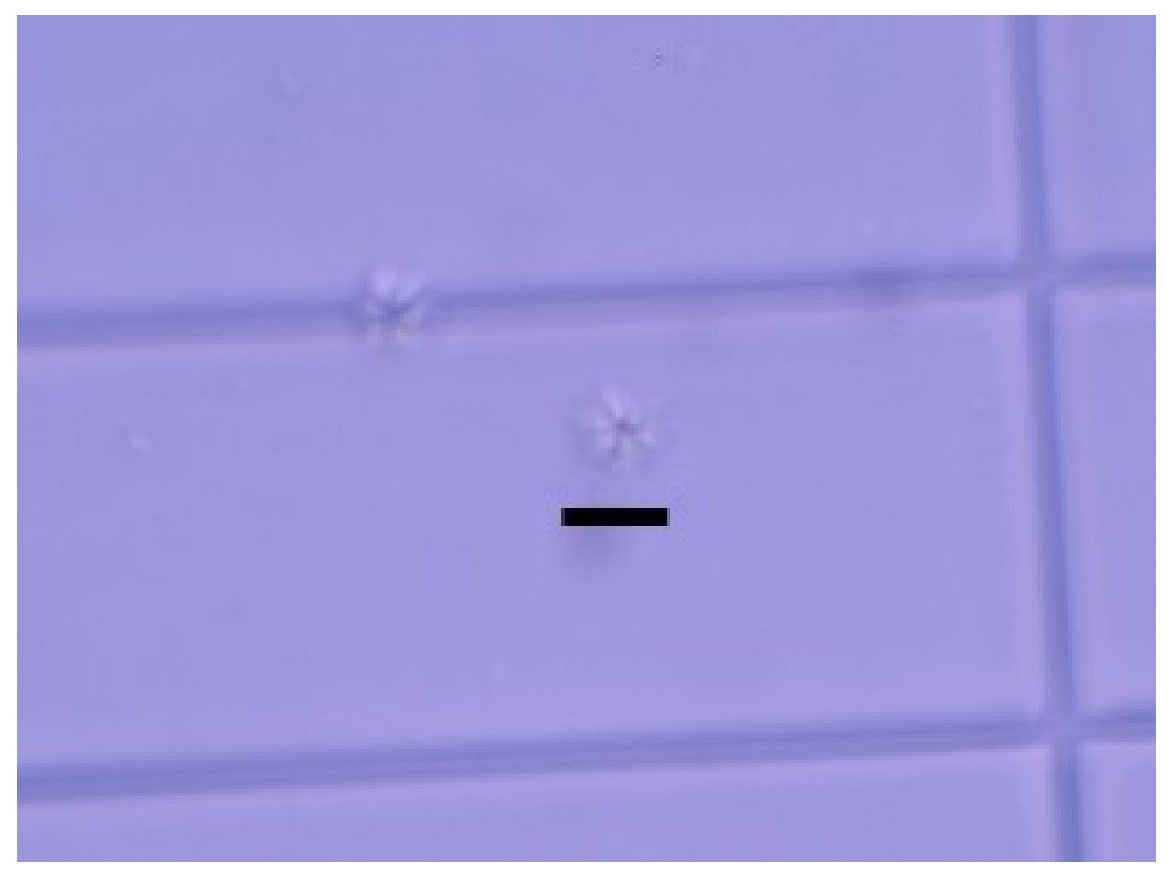

Fig. 1 Kudoa hexapunctata spores. K. hexapunctataspores harvested from juvenile Pacific bluefin tuna muscles from the sashimi leftovers. Scale bar: $10 \mu \mathrm{m}$. 